\title{
Performance Characteristics of Pyrazole as an Effective Dopant in a Blended Polymer Electrolyte for Nanocrystalline Dye-Sensitized Solar Cell Applications
}

\author{
S. AMUDHA*, S. AUSTIN SUTHANTHIRARAJ and P. MARUTHAMUTHU \\ Department of Energy, University of Madras, Guindy Campus, Chennai-600 025, India \\ amudha.sbs@gmail.com
}

Received 18 December 2012 / Accepted 13 January 2013

\begin{abstract}
Thin films of nanocomposite blended solid polymer electrolyte consisting of polymethyl methacrylate (PMMA)/polyvinylidene fluoride (PVDF), potassium iodide (KI) and iodine $\left(\mathrm{I}_{2}\right)$ as redox couple and pyrazole (PYR) as dopant were prepared using solution casting technique. The consequences of inclusion of PYR within PMMA/PVDF/KI/I $\mathrm{I}_{2}$ were investigated in terms of photovoltaic performance of the cell whereas the PYR impregnated polymer electrolyte solution when introduced into dye-sensitized solar cells (DSSCs) exhibited an overall energy-conversion efficiency of $5.5 \%$ at room temperature under AM1.5 illumination.
\end{abstract}

Keywords: Polymer electrolyte, Thin film, Redox couple, Solution casting

\section{Introduction}

At present a good deal of attention is being paid to dye-sensitized solar cells (DSSCs) because of their advantages over conventional silicon solar cells which include low cost, trouble-free fabrication process, high energy conversion efficiency and significant production ${ }^{1}$. A typical DSSC consists of a dye-sensitized $\mathrm{TiO}_{2}$ wide band gap semiconductor layer on a semi-transparent photo-anode, redox electrolyte $\left(\mathrm{I}^{-} / \mathrm{I}_{3}^{-}\right)$for hole transport and a platinum coated counter electrode acting as a photocathode ${ }^{2}$. The electrolyte operates as one of the major factors in endowing interior electrical conductivity by disseminating within the $\mathrm{TiO}_{2}$ semiconductor layer and is an important component in determining the cell performance ${ }^{3}$. However, practical problems such as leakage of liquid electrolyte remain as obstacles to their effective application aspects. As for as long-term stability of the solar cell is considered, use of liquid electrolytes must be avoided as the organic solvents evaporate slowly leading to decrease in the overall cell performance. Hence, in order to improve the long-standing stability of the solar cell, polymer electrolytes such as polyvinylidene fluoride-co-hexafluoro propylene (PVDF-HFP) ${ }^{4}$, poly(acrylonitrile $)^{5}$, poly(ethyleneoxide $)^{6}$ and polymethyl methacrylate (PMMA) ${ }^{7}$ with different plasticizers have been employed. Nowadays, blending of polymers is widely employed in preparing polymer electrolyte solutions in order to achieve better electrical properties which in turn are expected to increase the stability and 
and efficiency of the fabricated dye-sensitized solar cell (DSSC). In this framework, we have preferred the PMMA/PVDF-based blended solid polymer electrolyte so as to prevent the electrolyte leakage, evaporation of solvent and improvement of mechanical stability. The fact that polyvinylidene fluoride (PVDF) has already been extensively used in combination with different polymer electrolytes and that the presence of fluorine atoms in PVDF molecule having the smallest ionic radius and largest electronegativity are expected to improve the ionic transport and reduce the recombination rate taking place between $\mathrm{TiO}_{2}$ semiconductor and polymer electrolyte interface in the case of a DSSC. An additional polymer namely polymethyl methacrylate (PMMA) is also of scrupulous interest due to its shapeless nature, high resistance, non-tacking characteristics, surface resistance, interesting optical properties and ability to exhibit an appreciably high room temperature electrical conductivity ${ }^{8}$.

In this endeavor it is intended to explore the influence of pyrazole (PYR) on PMMA/PVDF-type blended solid polymer electrolytes and hence their performance in nanocrystalline $\mathrm{TiO}_{2}$ dye-sensitized solar cells (DSSCs) has been investigated. In general, molecular iodine $\left(\mathrm{I}_{2}\right)$ forms a charge-transfer complex with pyrazole thereby decreasing the problems of sealing and stability to a superior extent, thus acquiescing an efficient performance of the dye sensitized solar cell. The incorporation of pyrazole and $\mathrm{I}^{-} / \mathrm{I}_{3}{ }^{-}$redox couple into the PMMA/PVDF-based blended solid polymer electrolyte is expected to increase the overall efficiency of the dye-sensitized solar cell in view of the fact that pyrazole (1,2 - diazole) has two nitrogen atoms in the five-membered heterocyclic ring that can each donate lone pair of electrons which may enhance the open circuit photo-voltage $\left(\mathrm{V}_{\mathrm{oc}}\right)$ of a solar cell as reported earlier by Kusama and Arakawa ${ }^{9}$. In order to characterize the chosen solid polymer electrolyte system and to understand its ion transport behavior, a series of physical techniques including x-ray diffraction (XRD) analysis, complex impedance spectroscopy and I-V measurements have been employed.

\section{Experimental}

Thin film specimens of solid polymer electrolyte comprising of $(0.1 \mathrm{~g}) \mathrm{PMMA} /(0.2 \mathrm{~g})$ $\mathrm{PVDF} /(0.03 \mathrm{~g}) \mathrm{KI} /(0.006) \mathrm{I}_{2}$ were prepared using "solution-cast" technique. Appropriate starting materials were mixed together and the mixture was stirred at $353 \mathrm{~K}$ for $2 \mathrm{~h}$ using dimethyl formamide (DMF) as the common solvent. Subsequently, various amounts of pyrazole (PYR) (i.e $\mathrm{x}=0.0008,0.006,0.011,0.016,0.021,0.026$ and $0.031 \mathrm{~g}$ respectively) were incorporated into the PMMA/PVDF/KI/I $\mathrm{I}_{2}$ mixture and the solution was again stirred thoroughly for about 2-3 h, poured onto glass petri dishes and allowed to evaporate the intermediate solvent DMF under vacuum at $333 \mathrm{~K}$ for $24 \mathrm{~h}$. Finally, free-standing highly transparent films of different compositions of the blended polymer electrolyte were obtained.

\section{Characterization of polymer electrolytes}

\section{$X$-ray diffraction studies}

The X-ray diffraction patterns of PMMA/PVDF/KI/I $/$ / $\mathrm{x}$ ) g PYR (where $0.0008 \leq \mathrm{x} \leq 0.031$ ) blended polymer electrolyte specimens were recorded using a Bruker Axs Model D8 Advance A01-1 Power $x$-ray diffraction system with copper $\mathrm{K}_{\alpha}$ radiation (wavelength $\lambda=1.5418 \AA$ ).

\section{Electrical conductivity studies}

The electrical conductivities $(\sigma)$ of PMMA/PVDF/KI/I $/(\mathrm{x})$ g PYR (where $0.0008 \leq \mathrm{x} \leq$ $0.031)$ polymer electrolyte complexes were evaluated from the complex impedance plots (i.e., plots of real (Z') and imaginary (Z') parts of impedance at room temperature (298 $\mathrm{K})$ using a computer-controlled Hewlett-Packard model HP4284A Precision LCR Meter. 
The impedance plots were recorded in the frequency range $20 \mathrm{~Hz}$ to $1 \mathrm{MHz}$ while the polymer films were sandwiched between silver electrodes during the conductivity analysis involving the cell geometry of $\mathrm{Ag} /$ polymer film/Ag with an electrode area of $0.5024 \mathrm{~cm}^{2}$ and the value of electrical conductivity $(\sigma)$ was calculated based on the equation ${ }^{10}$;

$$
\sigma=\frac{t}{A, R_{b}}
$$

Where $\mathrm{t}$ is the thickness of the sample, A the area of cross-section and $\mathrm{R}_{\mathrm{b}}$ is the bulk resistance.

\section{Dye-sensitized solar cell (DSSC) assembly and characterization}

The archetype photoelectrochemical cells were designed and fabricated with [Cisdi(thiocyanato)- $N, N$-bis (2,2'-bipyridyl-4,4'-dicarboxylic acid) ruthenium (II)] dihydrate (N3 dye) as sensitizer, mesoporous $\mathrm{TiO}_{2}$ as photoanode and platinum as photocathode. DSSCs having an active area of $1 \mathrm{~cm}^{2}$ were constructed according to the procedure as described earlier ${ }^{10}$ and each cell had the following configuration:

\section{$\mathrm{TiO}_{2} / \mathrm{N} 3$ dye/PMMA/PVDF/KI/I $/ 2 / \mathrm{PYR} / \mathrm{Pt}$}

The current-voltage (I-V) curves were recorded for such cells at AM 1.5 illumination using a BAS100A Electrochemical Analyzer with 150W Xenon flash lamp as light source at $50 \mathrm{~mW} / \mathrm{cm}^{2}$.

\section{Results and Discussion}

XRD analysis

Figure 1 presents the $\mathrm{x}$-ray diffraction patterns obtained for thin film samples of blended electrolyte samples containing different compositions of the system i.e. PMMA/PVDF/ $\mathrm{KI} / \mathrm{I}_{2} /(\mathrm{x}) \mathrm{g} \mathrm{PYR}$ (where $\mathrm{x}=0.0008,0.006,0.011,0.016,0.021,0.026$ and 0.031 respectively). From Figure 1 , it is clear that an intense diffraction peak observed at $2 \theta=20.5^{\circ}[110]$ corresponds to $\beta$-phase of pure $\mathrm{PVDF}^{11}$ whereas those peaks at $2 \theta=18.5^{\circ}[020]$ and $26.4^{\circ}$ [022] correspond to $\alpha$-phase PVDF $^{12}$.

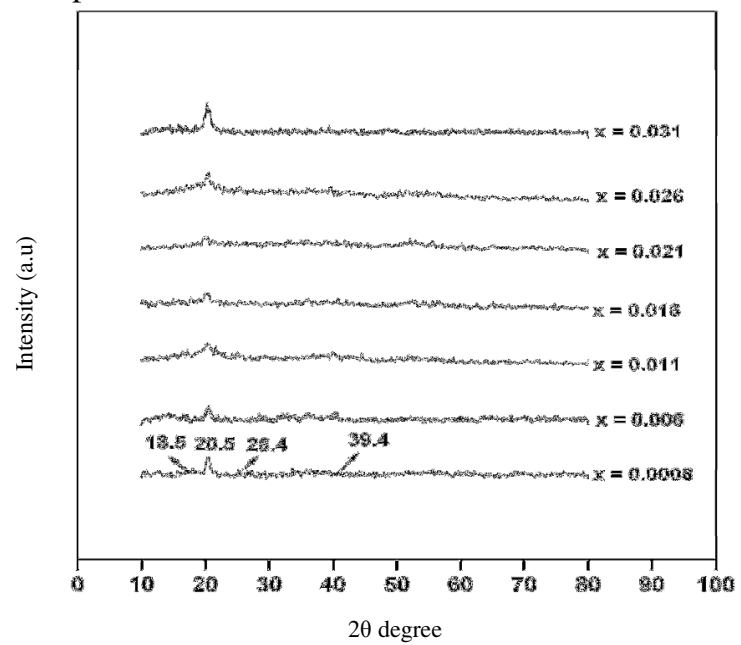

Figure 1. X-ray diffraction patterns observed for PMMA/PVDF/KI $/ \mathrm{I}_{2} /(\mathrm{x}) \mathrm{g}$ PYR blended polymer electrolyte system where $0.0008 \leq \mathrm{x} \leq 0.031$ 
It also reveals that the diffraction peak appearing at $2 \theta=39.4^{\circ}$ may be attributed to $\gamma$-phase $\mathrm{PVDF}^{12}$. It is observed that an intense sharp peak relative to $2 \theta=20.5^{\circ}$ corresponding to pure $\beta$-PVDF is altered after the incorporation of KI and $\mathrm{I}_{2}$. In addition to that, those diffraction peaks noticed at $2 \theta=18.5^{\circ}$ and $26.4^{\circ}$ departed after the inclusion of $\mathrm{KI}$ and $\mathrm{I}_{2}$. It is also evident that as a result of incorporation of various concentrations of pyrazole (PYR) into $\mathrm{PMMA} / \mathrm{PVDF} / \mathrm{KI} / \mathrm{I}_{2}$ the intensity of the peaks corresponding to $2 \theta=20.5^{\circ}$ is greatly reduced for the sample containing $\mathrm{X}=0.016 \mathrm{~g}$ PYR thus indicating that the complexation has taken place between PMMA/PVDF, KI, $\mathrm{I}_{2}$ and PYR and the observed decrease in intensity may be due to the crystalline changes taking place within PYR and PMMA/PVDF polymer blends. These results may be associated with Hodge et al ${ }^{13}$ principle which ascertains a correlation between the height of the diffraction peak and extent of crystallinity. The above results thus suggest that as the amorphous nature increases the ionic mobility is expected to increase which in turn increases the efficiency of the fabricated dye-sensitized solar cell (DSSC) as evidenced from the present conductivity and I-V measurements.

\section{Conductivity data}

A set of typical complex impedance plots obtained for the PMMA/PVDF/KI/I $/(\mathrm{x}) \mathrm{g}$ PYR (where $x=0.0008,0.006,0.011,0.016,0.021,0.026$ and 0.031 respectively) blended polymer electrolyte system are shown in Figures $2 \mathrm{a}$ and $2 \mathrm{~b}$. The values of room temperature electrical conductivity $\left(\sigma_{298} \mathrm{~K}\right)$ of these complexes are listed in Table 1 and found to be of the order of $10^{-7} \mathrm{Scm}^{-1}$ for PMMA/PVDF/KI/I/2/0.0008 PYR complex and increase up to $10^{-4} \mathrm{Scm}^{-1}$ for the best conducting PMMA/PVDF/KI/I $/ 2 / 0.016 \mathrm{~g}$ PYR blended polymeric complex. These values have indicated an enhancement by three orders of magnitude when compared to PMMA/PVDF/KI/I $/ 2 / 0.0008 \mathrm{PYR}$ and the observed increase in ionic conductivity may be explained by free volume theory. Consequent to the incorporation of dopant PYR into $\mathrm{PMMA} / \mathrm{PVDF} / \mathrm{KI} / \mathrm{I}_{2}$ blended polymer electrolyte complex the free volume increases between the polymer chains along with rotation of polymer chains and the rapid movement of ions takes place within the complex and hence the conductivity increases ${ }^{14}$. These outcomes are found to be in good agreement with the present XRD results.
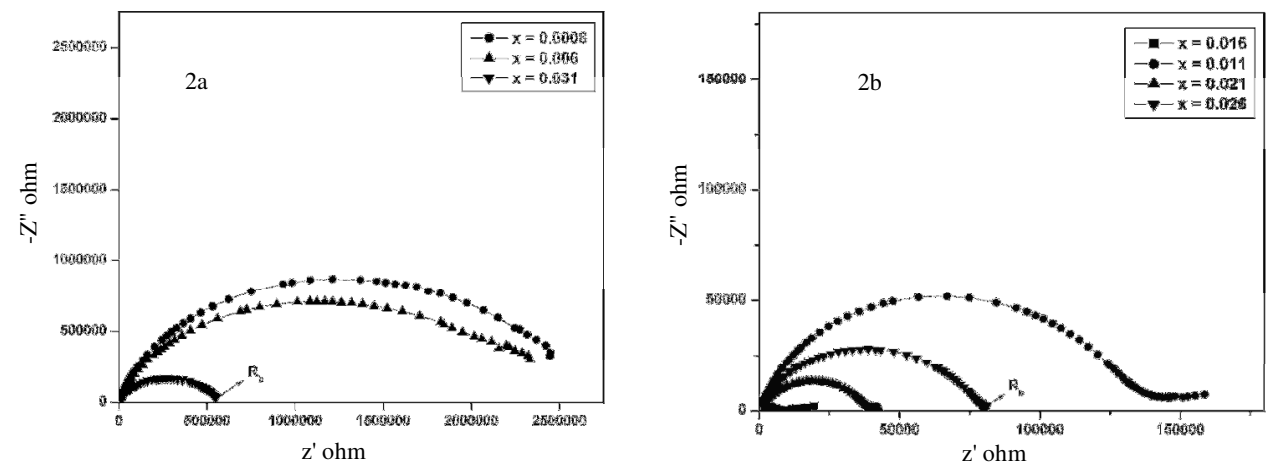

Figure 2. Complex impedance plots obtained for the PMMA/PVDF/KI/I $/(\mathrm{x}) \mathrm{g} P Y R$ blended polymer electrolyte system $\mathrm{a} . \mathrm{x}=0.0008,0.006$ and $0.031 \mathrm{~b} . \mathrm{x}=0.016,0.011,0.021$ and 0.026

\section{Photocurrent-voltage characteristics}

The photocurrent density-voltage curves of dye-sensitized solar cells (DSSCs) having $\mathrm{PMMA} / \mathrm{PVDF} / \mathrm{KI} / \mathrm{I}_{2} /(\mathrm{x}) \mathrm{g}$ PYR $($ where $\mathrm{x}=0.0008,0.006,0.011,0.016,0.021,0.026$ and 0.031 
respectively) blended polymer electrolyte system are presented in Figure 3 and the photovoltaic parameters are summarized in Table 1. From Table 1, it is clear that both ionic conductivity $(\sigma)$ and energy conversion efficiency $(\eta)$ increase with the addition of pyrazole (PYR). These results strongly elucidate that the cell performance depends on $\mathrm{I}^{-} / \mathrm{I}_{3}{ }^{-}$redox couple and concentration of the dopant PYR. Here the molecular iodine forms a chargetransfer complex with lone pair of electrons in PYR which enhances the open-circuit voltage and short-circuit current density of the solar cell ${ }^{15-16}$. In general PVDF is a semicrystalline polymer and incorporation of pyrazole (PYR) into blended polymer electrolyte complex produces immense structural changes within the polymer electrolyte whereas pyrazole being a pyridine derivative has more number of nitrogen atoms which can easily interact with $\mathrm{I}_{2}$ thereby decreasing the sublimation of $\mathrm{I}_{2}$ to a significant extent ${ }^{17}$. An optimum performance of $5.5 \%$ efficiency is obtained for the solar cell device assembled with the blended polymer electrolyte sample containing $x=0.016$ PYR. On the other hand, it is clear that increase in the conductivity of the electrolyte increases the efficiency of dye-sensitized solar cells to a considerable extent as evidenced from conductivity data. From these findings, it is clear that the dye-sensitized solar cell assembled with blended solid polymer electrolyte is a promising candidate for practical solar cell applications with good durability.

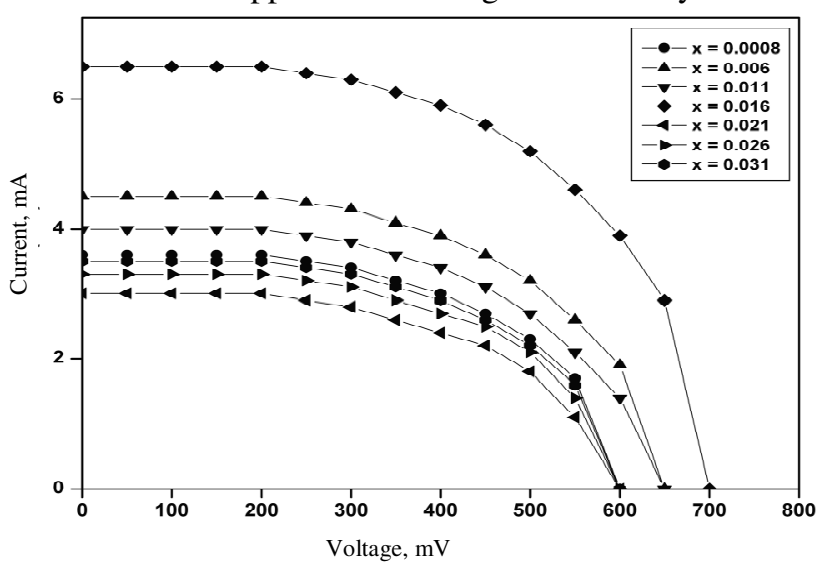

Figure 3. Current density $v s$. voltage curves obtained for the PMMA/PVDF/KI/I $/ 2 /(\mathrm{x}) \mathrm{g} \mathrm{PYR}$ blended polymer electrolyte system where $0.0008 \leq \mathrm{x} \leq 0.031$

Table 1. Room temperature ionic conductivity $\left(\sigma_{298 \mathrm{~K}}\right)$ and photo-electrochemical parameters evaluated for dye-sensitized solar cell having PMMA/PVDF/KI/I $/(\mathrm{x})$ g PYR blended polymer electrolyte system where $0.0008 \leq \mathrm{x} \leq 0.031$

\begin{tabular}{cccccc}
\hline $\begin{array}{c}\text { Composition, } \\
\mathrm{g}\end{array}$ & $\begin{array}{c}\text { Ionic } \\
\text { conductivity } \\
\sigma_{298 \mathrm{~K}}, \mathrm{Scm}^{-1}\end{array}$ & $\begin{array}{c}\text { Open-circuit } \\
\text { voltage } \\
\mathrm{V}_{\mathrm{oc}}, \mathrm{mV}\end{array}$ & $\begin{array}{c}\text { Short-circuit } \\
\text { current density } \\
\mathrm{J}_{\mathrm{sc}}, \mathrm{mA} / \mathrm{cm}^{2}\end{array}$ & $\begin{array}{c}\text { Fill } \\
\text { factor, } \\
\mathrm{ff}\end{array}$ & $\begin{array}{c}\text { Efficiency } \\
\eta, \%\end{array}$ \\
\hline $\mathrm{x}=0.0008$ & $7.2 \times 10^{-7}$ & 600 & 3 & 0.5 & 2 \\
$\mathrm{x}=0.006$ & $2.8 \times 10^{-7}$ & 600 & 3.3 & 0.6 & 2.4 \\
$\mathrm{x}=0.011$ & $4.2 \times 10^{-6}$ & 600 & 3.5 & 0.6 & 2.6 \\
$\mathrm{x}=0.016$ & $1.4 \times 10^{-4}$ & 700 & 6.5 & 0.6 & 5.5 \\
$\mathrm{x}=0.021$ & $2.6 \times 10^{-6}$ & 600 & 3.6 & 0.5 & 2.5 \\
$\mathrm{x}=0.026$ & $1.5 \times 10^{-5}$ & 650 & 4.5 & 0.5 & 2.8 \\
$\mathrm{x}=0.031$ & $1.5 \times 10^{-5}$ & 650 & 4 & 0.6 & 3.1 \\
\hline
\end{tabular}




\section{Conclusion}

PMMA/PVDF-based blended solid polymer electrolytes were prepared using solution casting technique and efficient dye-sensitized solar cells (DSSCs) have been fabricated. The introduction of pyrazole (PYR) dopant completely disrupted the crystalline structure of PMMA/PVDF and inter-segmental spacing as revealed by XRD results whereas the electrical conductivity data obtained as a task of concentration show the maximum room temperature electrical conductivity of $1.4 \times 10^{-4} \mathrm{Scm}^{-1}$. The typical DSSC employing $0.016 \mathrm{~g}$ PYR into the PMMA/PVDF/KI/I 2 blended polymer electrolyte sample exhibited the highest energy conversion efficiency of $5.5 \%$ at $50 \mathrm{~mW} / \mathrm{cm}^{2}$.

\section{References}

1. Park J H, Nhob Y C and Kan M G, J Photochem Photobiol A: Chem., 2009, 203(2-3), 151-154.

2. Wang J and Lin Z, Chem Mater., 2010, 22(2), 579-584.

3. Wang Y, Sol Energy Mater Sol Cells, 2009, 93(8), 1167-1175.

4. Lee K M, Suryanarayanan V and Ho K C, J Power Sources, 2008, 185(2), 1605-1612.

5. Shaheer Akhtar M, Li Z Y, Park D M, Oh D W, Kwak D H and Yang O B, Electrochim Acta, 2011, 56(27), 9973-9979.

6. Shaheer Akhtar M, Cheralathan K K, Chun J M and Yang O B, Electrochim Acta, 2008, 53(22), 6623-6628.

7. Biancardo M, West K and Krebs F C, Sol Energy Mater Sol Cells, 2006, 90(16), 2575-2588.

8. Sivakumar M, Subadevi R, Rajendran S, Wu H C and Wu N L, Euro Polym J., 2007, 43(10), 4466-4473.

9. Kusama H and Arakawa H, Sol Energy Mater Sol Cells, 2004, 81(1), 87-99.

10. Ganesan S, Muthuraaman B, Vinod Mathew, Kumara Vadivel M, Maruthamuthu P, Ashokkumar A and Austin Suthanthiraraj S, Electrochim Acta, 2011, 56(24), 8811-8817.

11. Saikia D and Kumar A, Electrochim Acta, 2004, 49(16), 2581-2589.

12. Elashmawi I S, Abdelrazek E M, Ragab H M and Hakeem N A, Physica B: Condensed Matter, 2010, 405, 94-98.

13. Hodge R M, Edward G H and Simon G P, Polymer, 1996, 37(8), 1371-1376.

14. Rajendran S, Mahendran O and Mahalingam T, Euro Polym J., 2002, 38(1), 49-55.

15. Greijer H, Lindgrev L and Hagfeldt A, J Phys Chem B, 2001, 105(27), 6314-6320.

16. He J, Benko G, Korodi F, Polivka T, Lomath R, Akermark B, Sur L, Hagfeldt A and Sundststrom V, J Am Chem Soc., 2002, 124(17), 4922-4932.

17. Ganesan S, Muthuraaman B, Madhavan J, Vinod Mathew, Maruthamuthu P and Austin Suthanthiraraj S, Electrochim Acta, 2008, 53(27), 7903-7907. 